\title{
Das Komposit ohne Kompromiss!
}

DENTSPLY's neues ceram. $\mathrm{x}^{\circledR}$ kombiniert Handlingkomfort mit natürlicher Ästhetik. Möglich ist dies dank der neuen zum Patent angemeldeten SphereTECTM-Füllertechnologie. Die sphärischen granulierten Füller erzeugen einen KugellagerEffekt und ermöglichen so eine gute Adaptation und Modellierbarkeit ohne am Handinstrument zu kleben. Die neue Produktgeneration wird in 5 universellen CLOUD-Farben A1 bis A4 angeboten. Diese

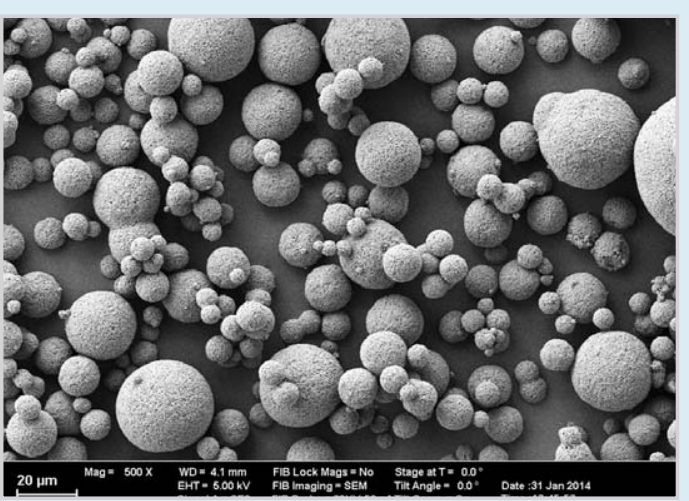

5 Farben decken das gesamte VITA ClassicSpektrum ab und sorgen dank ihres ausgeprägten Chamäleon-Effekts für ästhetische klinische Ergebnisse. Dazu tragen auch die primären Submikron-Glasfüller bei, die ein schnelles und einfaches Polieren ermöglichen.

Zur Markteinführung im September gibt es ein besonders attraktives Angebot: Die Starterpackung mit 24 Compules in allen 5 Farben gibt es zusammen mit einer Testpackung zum risikofreien Ausprobieren! Sollte das neue ceram.x wider Erwarten nicht gefallen, kann die Einführungspackung zurückgegeben werden, und der Kaufpreis wird erstattet. Weitere Informationen zum neuen Komposit sind beim DENTSPLY Service Center unter der gebührenfreien Rufnummer 08000/735000 sowie im Internet unter www.dentsplyspheretec.com abrufbar.

Nach einer Pressemitteilung der

Dentsply DeTrey, Konstanz 